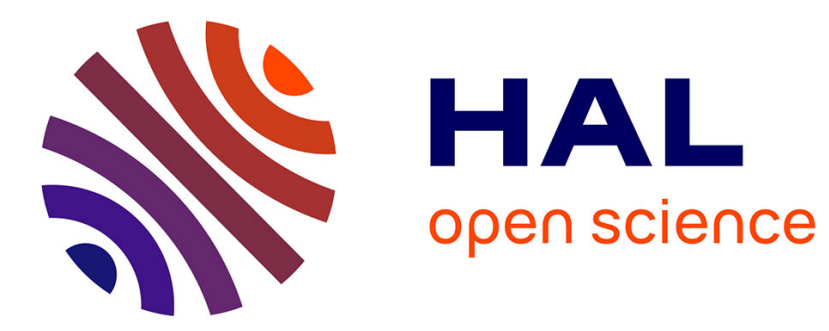

\title{
Tunable double photochromism of a family of bis-DTE bipyridine ligands and their dipolar Zn complexes.
}

\author{
Lucie Ordronneau, Vincent Aubert, Rémi Métivier, Eléna Ishow, Julien \\ Boixel, Keitaro Nakatani, Fatima Ibersiene, Dalila Hammoutène, Abdou \\ Boucekkine, Hubert Le Bozec, et al.
}

\section{To cite this version:}

Lucie Ordronneau, Vincent Aubert, Rémi Métivier, Eléna Ishow, Julien Boixel, et al.. Tunable double photochromism of a family of bis-DTE bipyridine ligands and their dipolar Zn complexes.. Physical Chemistry Chemical Physics, 2012, 14 (8), pp.2599-605. 10.1039/c2cp23333a . hal-00831009

\section{HAL Id: hal-00831009 \\ https://hal.science/hal-00831009}

Submitted on 9 Sep 2013

HAL is a multi-disciplinary open access archive for the deposit and dissemination of scientific research documents, whether they are published or not. The documents may come from teaching and research institutions in France or abroad, or from public or private research centers.
L'archive ouverte pluridisciplinaire HAL, est destinée au dépôt et à la diffusion de documents scientifiques de niveau recherche, publiés ou non, émanant des établissements d'enseignement et de recherche français ou étrangers, des laboratoires publics ou privés. 


\title{
Tunable double photochromism of a family of bis-DTE bipyridine ligands and their dipolar $\mathrm{Zn}$ complexes $\dagger$
}

\author{
Lucie Ordronneau, ${ }^{a}$ Vincent Aubert, ${ }^{a}$ Rémi Métivier, ${ }^{*} b$ Eléna Ishow, ${ }^{b}$ \\ Julien Boixel, ${ }^{b}$ Keitaro Nakatani, ${ }^{b}$ Fatima Ibersiene, ${ }^{a c}$ Dalila Hammoutène, ${ }^{c}$ \\ Abdou Boucekkine, ${ }^{a}$ Hubert Le Bozec ${ }^{a}$ and Véronique Guerchais ${ }^{* a}$ \\ Received 21st October 2011, Accepted 6th December 2011 \\ DOI: $10.1039 / \mathrm{c} 2 \mathrm{cp} 23333 \mathrm{a}$
}

The photoinduced ring-closure/ring-opening reactions of a series of bis-dithienylethene derivatives, as free ligands and $\mathrm{Zn}$ (II)-complexes, are investigated by resorting to theoretical (time-dependent density functional theory) and kinetic analyses in solution. The originality of the system stems from the tunability of the photoreaction quantum yields and conversion yields as a function of the electronic structure. The latter could be varied by modifying the electron-donating character of the DTE-end substituents $\mathbf{L}^{\mathbf{a}-\mathbf{d}}(\boldsymbol{o}, \boldsymbol{o})\left(\mathbf{a}, \mathrm{D}=\mathrm{H} ; \mathbf{b}, \mathrm{D}=\mathrm{OMe} ; \mathbf{c}, \mathrm{D}=\mathrm{NMe}_{2} ; \mathbf{d}\right.$, $\left.\mathrm{D}=\mathrm{NBu}_{2}\right)$ and $/$ or the Lewis character of the metal ion center $\mathbf{L}^{\mathrm{a}-\mathrm{d}} \mathbf{Z n X} \mathbf{X}_{\mathbf{2}}(\boldsymbol{o}, \boldsymbol{o})\left(\mathbf{L}^{\mathrm{a}-\mathbf{c}}, \mathbf{X}=\mathrm{OAc} ; \mathbf{L}^{\mathbf{d}}\right.$, $\mathrm{X}=\mathrm{Cl})$. The orbital description of the doubly-open form $(\boldsymbol{o}, \boldsymbol{o})$ and half-closed form $(\boldsymbol{o}, \boldsymbol{c})$ predicts that double closure to the form $(\boldsymbol{c}, \boldsymbol{c})$ would occur using UV irradiation. Photokinetic studies on the complete series demonstrate that photocyclization proceeds following a sequential ring closure mechanism. They clearly point out distinct quantum yields for the first and second ring closures, the latter being characterized by a significantly lower value. Dramatic decrease in both the quantum yields of the ring-closure and ring-opening processes is demonstrated for the complex $\mathbf{L}^{\mathbf{d}} \mathbf{Z n C l}_{\mathbf{2}}$ exhibiting the strongest charge-transfer character in the series investigated. These studies show that this series of DTE derivatives provides an efficient strategy to tune the photochromic properties through the combination of the electron-donor and electron-acceptor (D-A) groups.

\section{Introduction}

Multi-photochromic systems incorporating dithienylethene (DTE) have been the subject of intense research during the last decade in terms of fundamental research and practical applications in the field of optical memories. ${ }^{1-3}$ The photoswitching of multiple DTE units within the same structure is of interest for the modulation of opto-electronic properties of supramolecular systems and materials such as $\pi$-conjugated polymers. ${ }^{4}$ However, multi-DTE systems often display partial photochromic activity. ${ }^{5-18}$ The mechanism of the inhibition of the photocyclization process was interpreted as a result of an

\footnotetext{
${ }^{a}$ UMR 6226 CNRS-Université de Rennes 1, Sciences Chimiques de Rennes, Campus de Beaulieu, 35042 Rennes, France.

E-mail: veronique.guerchais@univ-rennes1.fr; Fax: + 33 223236939; Tel: +33223236729

${ }^{b}$ Laboratoire de Photophysique et Photochimie Supramoléculaires et Macromoléculaires, UMR CNRS 8531, Cachan, France.

E-mail: metivier@ppsm.ens-cachan.fr; Fax: +33 147402454; Tel: + 33147405594

${ }^{c}$ Laboratoire de Thermodynamique et Modélisation Moléculaire, Faculté de Chimie, USTHB 16111 Alger, Algérie

$\dagger$ Electronic supplementary information (ESI) available: Relevant frontier $\mathbf{M O}$ for $\mathbf{L}^{\mathbf{c}}$ and $\mathbf{L}^{\mathbf{c}} \mathbf{Z n} \mathbf{X}_{\mathbf{2}}$, selected experimental and theoretical electronic spectra, selected ${ }^{1} \mathrm{H}$ NMR spectra and photokinetic details. See DOI: $10.1039 / \mathrm{c} 2 \mathrm{cp} 23333 \mathrm{a}$
}

intramolecular energy transfer process from the Intra-Ligand $\mathrm{IL}(o$-DTE) state of the open-DTE to the lower energy IL(c-DTE) state of the adjacent $\pi$-conjugated closed-DTE unit. ${ }^{6-10,18}$ Complete photocyclization has been, however, reported in several cases, even for compounds incorporating up to six DTE units. ${ }^{19-27}$ In order to determine the parameters that govern the photochromic properties, the structure and electronic properties of various multi-dithienylethenes, electronically coupled or not, have been investigated with a computational approach. ${ }^{28-31}$

In the context of the modulation of nonlinear optical properties of polypyridyl metal complexes, we have designed and synthesized photochromic 4,4'-bis(ethenyl)-2,2'-bipyridine ligands functionalized by a dithienylethene (DTE) group $\left(\mathbf{L}^{\mathbf{a}, \mathbf{c}}\right)\left(\mathbf{a}, \mathrm{D}=\mathrm{H} ; \mathbf{c}, \mathrm{D}=\mathrm{NMe}_{2}\right)$ and their corresponding dipolar (bipyridyl)zinc(II)acetato complexes $\mathbf{L}^{\mathbf{a}, \mathbf{c}} \mathbf{Z n}(\mathbf{O A c})_{2}$ (Scheme 1). ${ }^{32}$ We found that the free ligands $\mathbf{L}^{\mathbf{a}, \mathbf{c}}$ and the corresponding complexes display a full photochromism, i.e. the two DTE units undergo ring-closure/opening processes. To gain further insight into this photochromic dynamics, we have investigated, by means of computational and kinetic studies using UV-vis absorption and NMR spectroscopy, the photochromic reactions of a family of bis-DTE species $\mathbf{L}^{\mathbf{a}-\mathbf{d}}$ and $\mathbf{L}^{\mathrm{a}-\mathrm{d}} \mathbf{Z n X}_{\mathbf{2}}(\mathrm{X}=$ OAc: $\mathbf{a}, \mathrm{D}=\mathrm{H} ; \mathbf{b}, \mathrm{D}=$ OMe; $\mathbf{c}, \mathrm{D}=$ $\mathrm{NMe}_{2} ; \mathrm{X}=\mathrm{Cl}$ : $\mathbf{d}, \mathrm{D}=\mathrm{NBu}_{2}$ ) whose electronic properties 


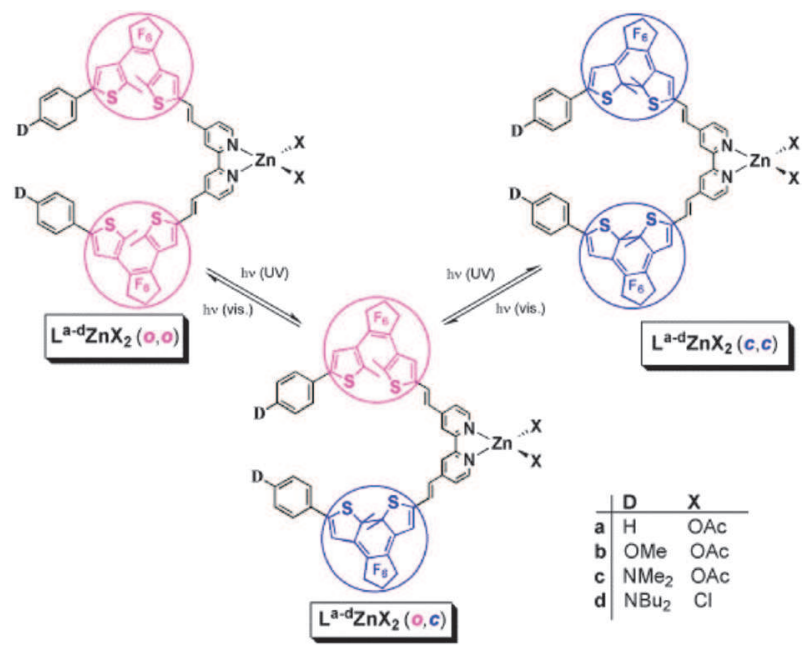

Scheme 1 Ring-closure and ring-opening reactions of the photochromic zinc complexes $\mathbf{L}^{\mathbf{a}-\mathbf{d}} \mathbf{Z n X _ { 2 }}$.

have been systematically modified by changing the nature of the end groups $\mathrm{D}$ and ancillary ligands $\mathrm{X}(\mathrm{X}=\mathrm{OAc}, \mathrm{Cl})$. This series of complexes is of special interest owing to the straightforward synthesis of combined D-A systems, as a strategy enabling tuning of their photochromic properties.

The adoption of a sequential two-step kinetic model for the conversion of the open-open $(\boldsymbol{o}, \boldsymbol{o})$ to the closed-closed form $(\boldsymbol{c}, \boldsymbol{c})$ allows us to rationalize the observed spectral absorption changes over irradiation time within the two series of compounds, clearly showing the accumulation of an openclosed form intermediate $(\boldsymbol{o}, \boldsymbol{c})$. In addition, we demonstrate the substantial electronic influence of the substituent D $(\mathrm{H}, \mathrm{OMe}$, $\mathrm{NMe}_{2}, \mathrm{NBu}_{2}$ ) on the quantum yields of both the ring-closure and ring-opening reactions, a significant decrease of the values being observed when the strength of the electron-donor group D increases. This trend is also reproduced in the series of $\mathrm{Zn}$ complexes and demonstrated by increasing the metal Lewis acid character. This is more clearly established in the case of the strong dipole $\mathbf{L}^{\mathbf{d}} \mathbf{Z n C l}_{\mathbf{2}}\left(\mathrm{D}=\mathrm{NBu}_{2}\right)$. These studies have been supported by theoretical investigations on the representative amino derivatives.

\section{Experimental}

\section{Density functional theory calculations}

The geometries of all compounds have been fully optimized using the PBE0 functional ${ }^{33}$ and the LANL2DZ basis set augmented with polarization functions on all atoms, except hydrogen ones with the Gaussian09 program. ${ }^{34}$ The computations of the electronic absorption spectra were carried out using TDDFT at the same level of theory with the same Gaussian09 package, utilising the previously optimized ground state geometries. Thirty states have been computed using TDDFT for each species except for $\mathbf{Z n L}^{\mathbf{c}}(\boldsymbol{o}, \boldsymbol{c})$, for which 40 states have been computed. Representation of molecular structures and orbitals was done using the Molekel program ${ }^{35}$ whereas theoretical absorption spectra were plotted using Swizard, ${ }^{36}$ the half-bandwidths for the Gaussian model being considered equal to $3500 \mathrm{~cm}^{-1}$. The cut-off used for the orbital representation is 0.05 a.u.

\section{Photokinetics}

Photochromic reactions were induced in situ by a continuous irradiation $\mathrm{Hg} / \mathrm{Xe}$ lamp (Hamamatsu, LC6 Lightningcure, $200 \mathrm{~W}$ ) equipped with narrow band interference filters of appropriate wavelengths. The irradiation power was measured using a photodiode from Ophir (PD300-UV). The photochromic quantum yields were determined by probing the sample with a Xenon lamp during the course of the light irradiation. Absorption changes were monitored by a CCDcamera mounted on a spectrometer (Princeton Instruments). Kinetic profiles were analyzed by means of a Runge-Kutta-based Igor-implemented home-made software.

As a first simple model, we initially assumed that both units would undergo photoinduced ring-closure reaction independently from each other. However, the Runge-Kutta numerical integration of the differential equation by considering the same quantum yields for the first step $(\boldsymbol{o}, \boldsymbol{o}) \rightarrow(\boldsymbol{o}, \boldsymbol{c})$ and the second step $(\boldsymbol{o}, \boldsymbol{c}) \rightarrow(\boldsymbol{c}, \boldsymbol{c})$ failed to provide a good agreement between simulated photokinetics and experimental data. As a consequence, the deviation between the experimental data and our first assumption prompted us to consider a sequential two-step kinetics characterized by two different quantum yields, as described in the Results and Discussion section.

\section{Results and discussion}

The preparation of $\mathbf{L}^{\mathbf{a}-\mathbf{d}}$ and $\mathbf{L}^{\mathbf{a}-\mathbf{d}} \mathbf{Z n} \mathbf{X}_{\mathbf{2}}$ has been described ${ }^{32}$ or will be reported elsewhere. Our synthetic approach provides various combinations of donor end groups and metal fragments. All these compounds undergo a double-closing behavior with excellent chemical conversions (80-95\%), as evidenced by ${ }^{1} \mathrm{H}$ NMR studies (for $\mathbf{L}^{\mathbf{d}}$, Fig. S1, ESI $\dagger$ ). To further understand the specific reactivity of the investigated photochromes, time-dependent density functional theory (TD-DFT) calculations were performed on the optimized geometries at the PBE0/LANL2DZ level of theory. We have focused our analyses on the representative photochromic dimethylamino derivative $\mathbf{L}^{\mathbf{c}}$ and its corresponding $\mathrm{Zn}(\mathrm{OAc})_{2}$ complex, in its three states, open-open $(\boldsymbol{o}, \boldsymbol{o})$, open-closed $(\boldsymbol{o}, \boldsymbol{c})$, and closed-closed $(\boldsymbol{c}, \boldsymbol{c})$. The computed data of oscillator strengths, energies and molecular orbital (MO) compositions of the electronic transitions for $\mathbf{L}^{\mathbf{c}}$ and $\mathbf{L}^{\mathbf{c}} \mathbf{Z n}(\mathbf{O A c})_{2}$ are listed in Tables 1 and 2, respectively. The significant frontier MOs of $\mathbf{L}^{\mathbf{c}}$ and $\mathbf{L}^{\mathbf{c}} \mathbf{Z n}(\mathbf{O A c})_{\mathbf{2}}$ are given in Fig. S2 and S3, ESI. $\dagger$

The computed electronic spectra of $\mathbf{L}^{\mathbf{c}}[(\boldsymbol{o}, \boldsymbol{o}),(\boldsymbol{o}, \boldsymbol{c})$ and $(\boldsymbol{c}, \boldsymbol{c})]$ are presented in Fig. 1. The electronic spectrum of $\mathbf{L}^{\mathbf{c}}(\boldsymbol{o}, \boldsymbol{o})$ exhibits an intense band in the UV region, attributed to $\pi \rightarrow \pi^{*}$ transitions centered on the open-DTE and bpy fragments. This intense absorption band is mainly composed of a combination of two transitions from the quasi-degenerated HOMO -2 $(\mathrm{HOMO}-3)$ to LUMO (LUMO +1$)$, respectively.

The HOMO - 2 (HOMO - 3) is delocalized over the vinylthiophene fragment of the photochromic unit with some contribution of pyridine rings whereas the LUMO has a strong bipyridine character. It is interesting to note that this absorption band also includes a contribution $(8 \%)$ of an electronic excitation from HOMO -2 to LUMO +2 (Fig. 2), this latter being almost exclusively localized on the 
Table 1 Partial molecular orbital composition for the three states $(\boldsymbol{o}, \boldsymbol{o} ; \boldsymbol{o}, \boldsymbol{c} ; \boldsymbol{c}, \boldsymbol{c})$ of $\mathbf{L}^{\mathrm{c}}$

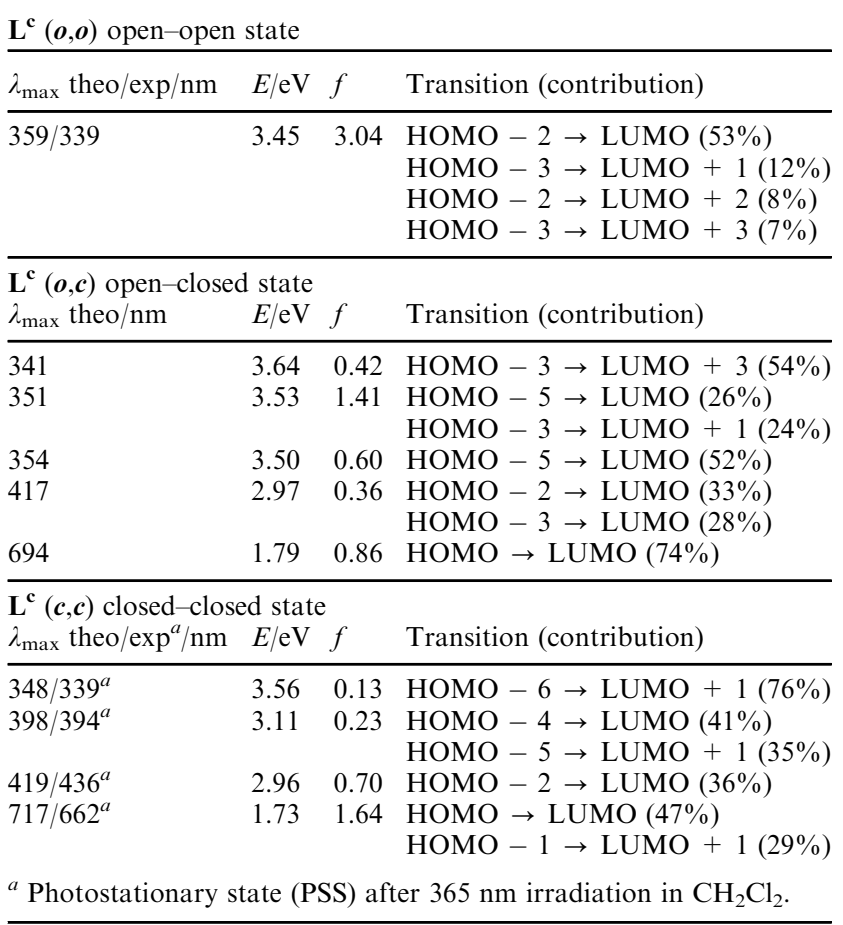

Table 2 Partial molecular orbital composition for the three states $(o, o ; o, c ; c, c)$ of $\mathrm{L}^{\mathrm{c}} \mathrm{Zn}(\mathrm{OAc})_{2}$

$\mathbf{L}^{\mathrm{c}} \mathbf{Z n}(\mathbf{O A c})_{2}(\boldsymbol{o}, \boldsymbol{o})$ open-open state

\begin{tabular}{llll}
\hline$\lambda$ theo/exp/nm & $E / \mathrm{eV}$ & $f$ & Transition (contribution) \\
\hline $379 / 360$ & 3.27 & 0.54 & HOMO $-7 \rightarrow$ LUMO $(80 \%)$ \\
$399 / 400$ & 3.10 & 0.52 & HOMO $-8 \rightarrow$ LUMO $(7 \%)$ \\
\hline
\end{tabular}

$\mathbf{L}^{\mathbf{c}} \mathbf{Z n}(\mathbf{O A c})_{2}(\boldsymbol{o}, \boldsymbol{c})$ open-closed state

\begin{tabular}{llll}
$\lambda$ theo $/ \mathrm{nm}$ & $E / \mathrm{eV}$ & $f$ & Transition (contribution) \\
\hline 371 & 3.34 & 1.08 & HOMO $-5 \rightarrow$ LUMO $+1(83 \%)$ \\
440 & 2.81 & 0.15 & HOMO $\rightarrow$ LUMO $+3(69 \%)$ \\
756 & 1.64 & 0.79 & HOMO $-4 \rightarrow$ LUMO $\rightarrow$ LUMO $(100 \%)$ \\
\hline
\end{tabular}

$\mathbf{L}^{\mathbf{c}} \mathbf{Z n}(\mathbf{O A c})_{\mathbf{2}}(\boldsymbol{c}, \boldsymbol{c})$ closed-closed state

$\lambda$ theo $/ \exp ^{\mathrm{a}} / \mathrm{nm} \quad E / \mathrm{eV} \quad f \quad$ Transition (contribution)

\begin{tabular}{llll}
\hline $459 / 398^{\mathrm{a}}$ & 2.84 & 0.29 & HOMO $-4 \rightarrow$ LUMO $+1(60 \%)$
\end{tabular}

$746 / 687^{\mathrm{a}} \quad 1.66 \quad 0.65$ HOMO $-1 \rightarrow$ LUMO $(84 \%)$

${ }^{a}$ Photostationary state (PSS) after $365 \mathrm{~nm}$ irradiation in $\mathrm{CH}_{2} \mathrm{Cl}_{2}$.

$\mathrm{C}=\mathrm{C}$ bond of the perfluorocyclopentene group. It can also be noted that the reactive carbon atoms contribute to the LUMO +2 by their $2 p \pi$ orbitals, suggesting that irradiation may be effective to close the DTE units. Moreover, the optimized geometry of $\mathbf{L}^{\mathbf{c}}(\boldsymbol{o}, \boldsymbol{o})$ shows that the $\mathrm{C}-\mathrm{C}$ bond distance $(3.587 \AA)$ between the two reactive carbon atoms is within the geometric range for closure. ${ }^{22}$

The calculated spectrum of the fully closed form $\mathbf{L}^{\mathbf{c}}(\boldsymbol{c}, \boldsymbol{c})$ is in reasonable agreement with the experimental one (Fig. 1 and Fig. S4, ESI $\dagger$ ). The band, peaking at $717 \mathrm{~nm}$ in the visible region, is related to a predominant contribution to $\mathrm{HOMO} \rightarrow$ LUMO transition, involving the closed-DTE units with some

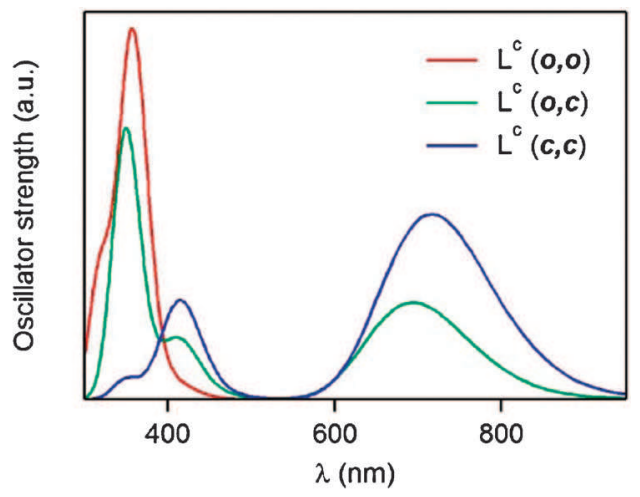

Fig. 1 Calculated absorption spectra for the three possible isomers of $\mathbf{L}^{\mathrm{c}}$.

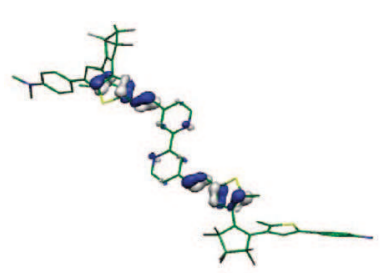

HOMO-2

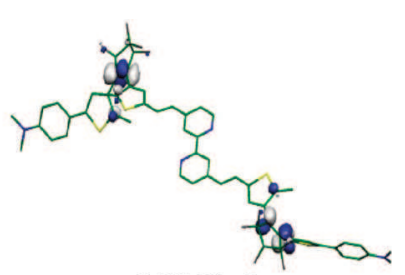

$\mathrm{LUMO}+2$
Fig. 2 Relevant frontier orbitals of $\mathbf{L}^{\mathbf{c}}(\boldsymbol{o}, \boldsymbol{o})$.

Table 3 Absorption maxima of $\mathbf{L}^{\mathbf{a}-\mathbf{d}}$ and $\mathbf{L}^{\mathbf{a}-\mathbf{d}} \mathbf{Z n X} \mathbf{X}_{\mathbf{2}}$ in $\mathrm{CH}_{2} \mathrm{Cl}_{2}$ in the photostationary state (PSS) after irradiation at $365 \mathrm{~nm}$

\begin{tabular}{ll}
\hline Compound & $\lambda_{\max } \exp / \mathrm{nm}$ \\
\hline $\mathbf{L}^{\mathbf{a}}(\mathrm{H})$ & 623 \\
$\mathbf{L}^{\mathbf{b}}(\mathrm{OMe})$ & 629 \\
$\mathbf{L}^{\mathbf{c}}\left(\mathrm{NMe}_{2}\right)$ & 669 \\
$\mathbf{L}^{\mathbf{d}}\left(\mathrm{NBu}_{2}\right)$ & 679 \\
$\mathbf{L}^{\mathbf{a}} \mathbf{Z n}(\mathbf{O A c})_{\mathbf{2}}$ & 628 \\
$\mathbf{L}^{\mathbf{b}} \mathbf{Z n}(\mathbf{O A c})_{\mathbf{2}}$ & 646 \\
$\mathbf{L}^{\mathbf{c}} \mathbf{Z n}(\mathbf{O A c})_{\mathbf{2}}$ & 687 \\
$\mathbf{L}^{\mathbf{d}} \mathbf{Z n C l} \mathbf{2}_{\mathbf{2}}$ & 714 \\
\hline
\end{tabular}

contribution from the amino group. The influence of the electron-donor end group D is reflected by the bathochromic shift of the experimental absorption band within the series $\mathrm{NBu}_{2}>\mathrm{NMe}_{2}>\mathrm{OMe}>\mathrm{H}$ (Table 3 ). This feature is in good agreement with the HOMO-LUMO gaps calculated for the closed forms $(\boldsymbol{c}, \boldsymbol{c})$ (Table S1, ESI $\dagger$ ). This trend is also reproduced in the $\mathrm{Zn}$ complexes (Fig. 3), illustrating the tunability of the photochromic properties of these D-A systems. For $\mathbf{L}^{\mathbf{c}}(\boldsymbol{o}, \boldsymbol{c})$, the mixed open-closed state has localized excited states; its electronic spectrum is the addition of the absorption bands of the two pyridine fragments in their open and closed states. The transition located in the visible (computed $\lambda_{\max }=694 \mathrm{~nm}$ ) mainly involves the HOMO $\rightarrow$ LUMO transition, those molecular orbitals being delocalized on the closed DTE fragment, as calculated in $\mathbf{L}^{\mathbf{c}}(\boldsymbol{c}, \boldsymbol{c})$. The simulated spectrum shows a red-shift $(23 \mathrm{~nm})$ of the visible absorption band upon going from $\mathbf{L}^{\mathbf{c}}(\boldsymbol{o}, \boldsymbol{c})(694 \mathrm{~nm})$ to $\mathbf{L}^{\mathbf{c}}(\boldsymbol{c}, \boldsymbol{c})$ $(717 \mathrm{~nm})$. Such a bathochromic shift has been previously observed experimentally ${ }^{37}$ and is well reproduced by theoretical calculations. $^{29}$

It is interesting to note that the UV absorption band has noticeable HOMO -3 to LUMO + $1(24 \%)$ and HOMO -3 


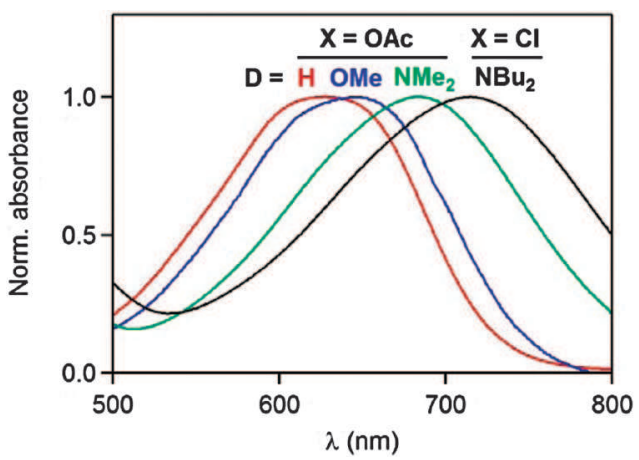

Fig. 3 Absorption spectra of $\mathbf{L}^{\mathbf{a}-\mathbf{d}} \mathbf{Z n X} \mathbf{X}_{\mathbf{2}}$ in $\mathrm{CH}_{2} \mathrm{Cl}_{2}$ at the PSS after irradiation at $365 \mathrm{~nm}$.

to LUMO $+3(54 \%)$ contributions to frontier orbitals localized on the open DTE. As in $\mathbf{L}^{\mathbf{c}}(\boldsymbol{o}, \boldsymbol{o})$, there is an electronic contribution for the reactive carbon atoms in LUMO +3 , the topology of the orbitals being suitable for a ring-closure reaction (Fig. 4). We can conclude that the photocyclization of the second DTE unit, in the intermediate state, is expected to be allowed on theoretical basis.

Analogous studies were extended to the corresponding complex $\mathbf{L}^{\mathbf{c}} \mathbf{Z n}(\mathbf{O A c})_{2}$, which displays a similar behavior. UV irradiation triggers both photocyclization processes with a high chemical conversion to $\mathbf{L}^{\mathbf{c}} \mathbf{Z n}(\mathbf{O A c})_{2} \quad(\boldsymbol{c}, \boldsymbol{c}) \quad(85-95 \%)$. The relevant orbitals and the computed electronic spectra are provided in Fig. S3 and S5, ESI. $\dagger$ The photochromic reactivity of $\mathbf{L}^{\mathbf{c}} \mathbf{Z n}(\mathbf{O A c})_{2}(\boldsymbol{o}, \boldsymbol{o})$ is mainly determined by the HOMO $-6 \rightarrow$ LUMO transition, from the $\pi$ orbitals of the vinylthiophene fragment to the $\pi^{*}$ orbitals of the bipyridyl rings (Table 2). As expected, complexation of $\mathbf{L}^{\mathbf{c}}(\boldsymbol{o}, \boldsymbol{o})$ to the Lewis acid fragment $\mathrm{Zn}(\mathrm{OAc})_{2}$ leads to an increased contribution of the pyridine fragments to the LUMO, as compared to the free ligand. The fully closed state $\mathbf{L}^{\mathbf{c}} \mathbf{Z n}(\mathbf{O A c})_{2}(\boldsymbol{c}, \boldsymbol{c})$ displays a band into the visible $(746 \mathrm{~nm})$ red-shifted compared to that in free $\mathbf{L}^{\mathbf{c}}(\boldsymbol{c}, \boldsymbol{c})(717 \mathrm{~nm})$. This band is typically related to HOMO (HOMO - 1) $\rightarrow$ LUMO + 1 (LUMO) excitations located on the closed-DTE fragments of the molecule. For the intermediate $\mathbf{L}^{\mathbf{c}} \mathbf{Z n}(\mathbf{O A c})(\boldsymbol{o}, \boldsymbol{c})$, we can note that the UV

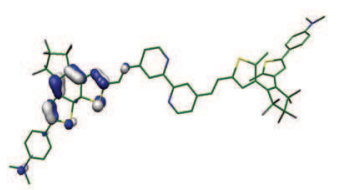

HOMO

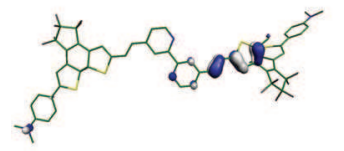

HOMO-3

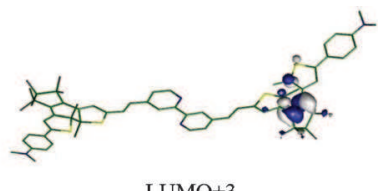

LUMO+3

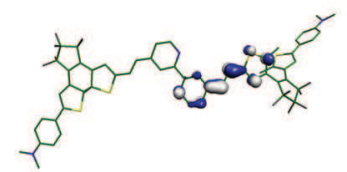

LUMO+1

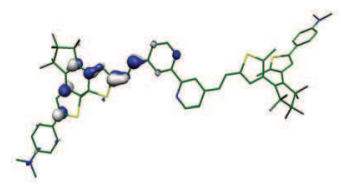

LUMO
Fig. 4 Relevant frontier orbitals of $\mathbf{L}^{\mathbf{c}}(\boldsymbol{o}, \boldsymbol{c})$. transition involves the LUMO +1 for which contribution is located on the open-DTE unit allowing further closure.

The theoretical studies are in good agreement with the experimental data available and are consistent with the double ring-closure photoinduced reactions observed experimentally (vide infra). The orbital features of $\mathbf{L}^{\mathbf{c}}(\boldsymbol{o}, \boldsymbol{o})$ and $\mathbf{L}^{\mathbf{c}}(\boldsymbol{o}, \boldsymbol{c})$, both as free ligands and $\mathrm{Zn}$ complexes, indicate that the doubly closed forms $(\boldsymbol{c}, \boldsymbol{c})$ could be photogenerated under UV irradiation (365 $\mathrm{nm}$ being used experimentally). Based on these theoretical predictions and in order to gain further insight into the mechanistic closing process operating for the biphotochromic compound of these series, we have investigated quantitatively the photoinduced formation of the $(\boldsymbol{c}, \boldsymbol{c})$ species in solution under light irradiation. We have measured the photochromic quantum yields by means of absorption spectroscopy and photokinetic models.

All the spectroscopic experiments were conducted in $\mathrm{CH}_{2} \mathrm{Cl}_{2}$ solutions $\left(1-3 \times 10^{-5} \mathrm{~mol} \mathrm{~L}^{-1}\right)$ under continuous irradiation at $\lambda=365 \mathrm{~nm}$ (respectively $\lambda=588$ or $650 \mathrm{~nm}$ ) to promote the cyclization (respectively retrocyclization) reactions. They have been performed on the two series of compounds, the free ligands $\mathbf{L}^{\mathbf{a}-\mathbf{d}}$ and their $\mathbf{Z n}$ complexes $\mathbf{L}^{\mathbf{a}-\mathbf{d}} \mathbf{Z n} \mathbf{X}_{\mathbf{2}}$. Given the symmetry of the compounds, it is reasonable to consider the following scheme:

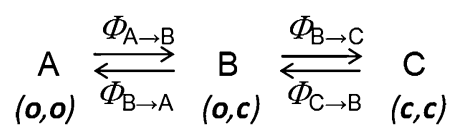

The photoinduced ring-closure and ring-opening reactions of the photochromic compounds have been monitored by a fast recording UV-vis absorption spectroscopy set-up under continuous light irradiation, and the data were analyzed using a home-made computational approach aiming at inferring the quantum yields and the time concentration evolution of the various photoisomers (eqn (1))

$$
\begin{aligned}
\frac{\mathrm{d} C_{i}(t)}{\mathrm{d} t}= & I_{0}\left(\lambda_{\mathrm{irr}}\right)\left(\frac{1-10^{-\mathrm{Abs}\left(\lambda_{\mathrm{irr}}, t\right)}}{\operatorname{Abs}\left(\lambda_{\mathrm{irr}}, t\right)}\right) \\
& \sum_{\substack{j=A, B, C \\
j \neq i \\
(i, j) \neq(A, C)}} \Phi_{j \rightarrow i} \varepsilon_{j}\left(\lambda_{\mathrm{irr}}\right) l C_{j}(t)-\Phi_{i \rightarrow j} \varepsilon_{i}\left(\lambda_{\mathrm{irr}}\right) l C_{i}(t)
\end{aligned}
$$

with

$$
\operatorname{Abs}\left(\lambda_{\mathrm{irr}}, t\right)=\sum_{i=A, B, C} \varepsilon_{i}\left(\lambda_{\mathrm{irr}}\right) l C_{i}(t)
$$

where $C_{i}(t)$ and $\varepsilon_{i}\left(\lambda_{\text {irr }}\right)$ designate the concentration and the molar absorption coefficient at the irradiation wavelength $\lambda_{\text {irr }}$ of the species $i$ (namely $(\boldsymbol{o}, \boldsymbol{o}),(\boldsymbol{o}, \boldsymbol{c})$, or $(\boldsymbol{c}, \boldsymbol{c})), I_{0}\left(\lambda_{\text {irr }}\right)$ features the incident energy at the irradiation wavelength, and $l$ is the optical pathway.

Given the lack of noticeable spectral shift of the visible absorption band related to the closed-DTE unit during irradiation, we presumed that the molar absorption coefficient of the $(\boldsymbol{o}, \boldsymbol{c})$ photoisomer could be regarded as half of the sum of the molar absorption coefficients of the $(\boldsymbol{o}, \boldsymbol{o})$ and $(\boldsymbol{c}, \boldsymbol{c})$ species. Satisfactory numerical fits of the time-evolution of the absorption data were obtained (Fig. 5 and Fig. S6, ESI $\dagger$, 

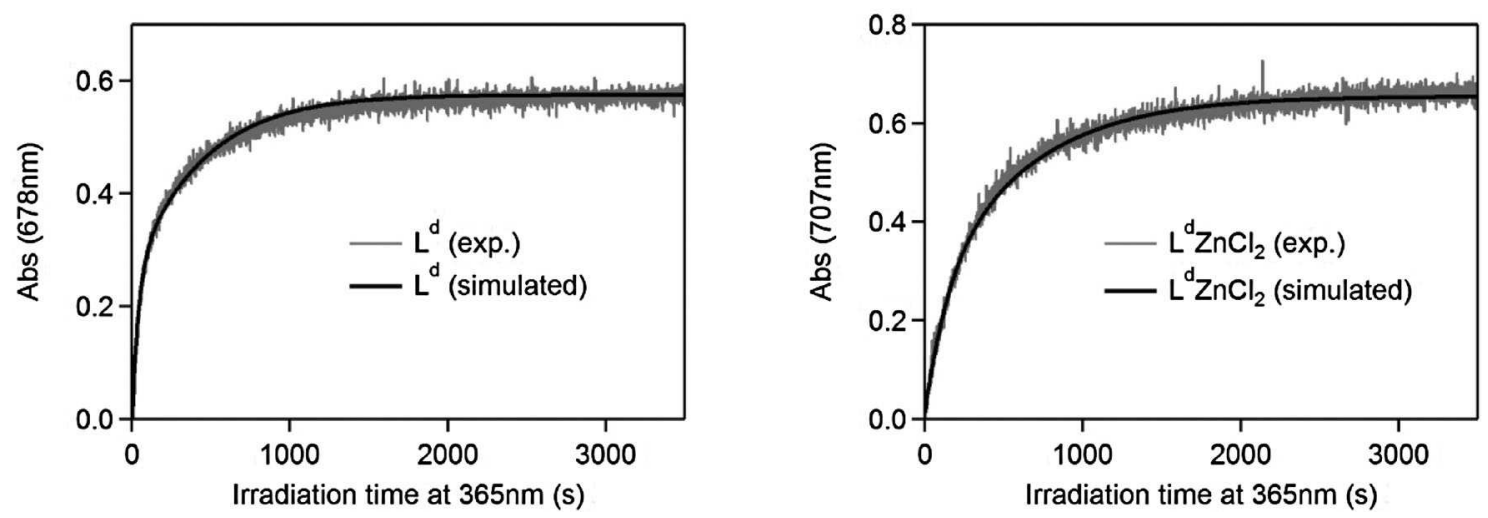

Fig. 5 Experimental and simulated evolution of absorbance of $\mathbf{L}^{\mathbf{d}}$ at $678 \mathrm{~nm}$ (left) and of $\mathbf{L}^{\mathbf{d}} \mathbf{Z n C l}_{\mathbf{2}}$ at 707 nm (right) as a function of irradiation time at $365 \mathrm{~nm}$.

for retrocyclization) and they revealed two different sets of quantum yields, the first one related to the $(\boldsymbol{o , o}) \rightarrow(\boldsymbol{o}, \boldsymbol{c})$ reaction being systematically larger by one order of magnitude than the second one describing the second ring-closure $(\boldsymbol{o}, \boldsymbol{c}) \rightarrow$ $(\boldsymbol{c}, \boldsymbol{c})$ (Table 4). It thus becomes clear that, although both photochromic reactions $(\boldsymbol{o}, \boldsymbol{o}) \rightarrow(\boldsymbol{o}, \boldsymbol{c})$ and $(\boldsymbol{o}, \boldsymbol{c}) \rightarrow(\boldsymbol{c}, \boldsymbol{c})$ can actually take place as anticipated by the DFT calculations

Table 4 Photoreaction quantum yields for $\mathbf{L}^{\mathbf{a}-\mathbf{d}}$ and $\mathbf{L}^{\mathbf{a}-\mathbf{d}} \mathbf{Z n X} \mathbf{X}_{\mathbf{2}}$ determined in $\mathrm{CH}_{2} \mathrm{Cl}_{2}$ by $\mathrm{UV}$-vis spectroscopy combined with a numerical fitting procedure

\begin{tabular}{|c|c|c|}
\hline Ligand & $\begin{array}{l}\Phi \text { Ring-closure }{ }^{a} \\
(\boldsymbol{o}, \boldsymbol{o}) \rightarrow(\boldsymbol{o}, \boldsymbol{c}) /(\boldsymbol{o}, \boldsymbol{c}) \rightarrow(\boldsymbol{c}, \boldsymbol{c})\end{array}$ & $\begin{array}{l}\Phi \text { Ring-opening } \\
(\boldsymbol{c}, \boldsymbol{c}) \rightarrow(\boldsymbol{o}, \boldsymbol{c}) /(\boldsymbol{o}, \boldsymbol{c}) \rightarrow(\boldsymbol{o}, \boldsymbol{o})\end{array}$ \\
\hline $\begin{array}{l}\mathbf{L}^{\mathbf{a}}(\mathrm{H}) \\
\mathbf{L}^{\mathbf{b}}(\mathrm{OMe}) \\
\mathbf{L}^{\mathbf{c}}\left(\mathrm{NMe}_{2}\right) \\
\mathbf{L}^{\mathbf{d}}\left(\mathrm{NBu}_{2}\right)\end{array}$ & $\begin{array}{l}0.83 / 0.16 \\
0.65 / 0.15 \\
0.58 / 0.043 \\
0.12 / 0.012\end{array}$ & $\begin{array}{l}3.4 \times 10^{-3} / 3.4 \times 10^{-3} \\
4.0 \times 10^{-3} / 4.0 \times 10^{-3} \\
2.2 \times 10^{-3} / 2.2 \times 10^{-3} \\
4.8 \times 10^{-4} / 4.8 \times 10^{-4}\end{array}$ \\
\hline Complex & $\begin{array}{l}\Phi \text { Ring-closure }{ }^{a} \\
(\boldsymbol{o}, \boldsymbol{o}) \rightarrow(\boldsymbol{o}, \boldsymbol{c}) /(\boldsymbol{o}, \boldsymbol{c}) \rightarrow(\boldsymbol{c}, \boldsymbol{c})\end{array}$ & $\begin{array}{l}\Phi \text { Ring-opening } \\
(\boldsymbol{c}, \boldsymbol{c}) \rightarrow(\boldsymbol{o}, \boldsymbol{c}) /(\boldsymbol{o}, \boldsymbol{c}) \rightarrow(\boldsymbol{o}, \boldsymbol{o})\end{array}$ \\
\hline $\begin{array}{l}\mathrm{L}^{\mathrm{a}} \mathrm{Zn}(\mathrm{OAc})_{2} \\
\mathrm{~L}^{\mathrm{b}} \mathrm{Zn}(\mathrm{OAc})_{2} \\
\mathrm{~L}^{\mathrm{c}} \mathrm{Zn}(\mathrm{OAc})_{2} \\
\mathrm{~L}^{\mathbf{d}} \mathrm{ZnCl} \mathbf{2}_{2}\end{array}$ & $\begin{array}{l}0.70 / 0.065 \\
0.52 / 0.055 \\
0.23 / 0.048 \\
0.0024 / 0.0005\end{array}$ & $\begin{array}{l}6.0 \times 10^{-3} / 6.0 \times 10^{-3} \\
4.0 \times 10^{-3} / 4.0 \times 10^{-3} \\
9.0 \times 10^{-4} / 9.0 \times 10^{-4} \\
1.3 \times 10^{-4} / 1.3 \times 10^{-4}\end{array}$ \\
\hline \multicolumn{3}{|c|}{$\begin{array}{l}{ }^{a} \text { Irradiation at } \lambda=365 \mathrm{~nm}^{b} \text { Irradiation at } \lambda=588 \mathrm{~nm}\left(\mathbf{L}^{\mathbf{a}-\mathbf{c}} \text { and }\right. \\
\left.\mathbf{L}^{\mathbf{a}-\mathbf{c}} \mathbf{Z n}(\mathbf{O A c})_{\mathbf{2}}\right) \text { or } \lambda=650 \mathrm{~nm}\left(\mathbf{L}^{\mathbf{d}} \text { and } \mathbf{L}^{\mathbf{d}} \mathbf{Z n C \mathbf { n } _ { \mathbf { 2 } } ) .}\right.\end{array}$} \\
\hline
\end{tabular}

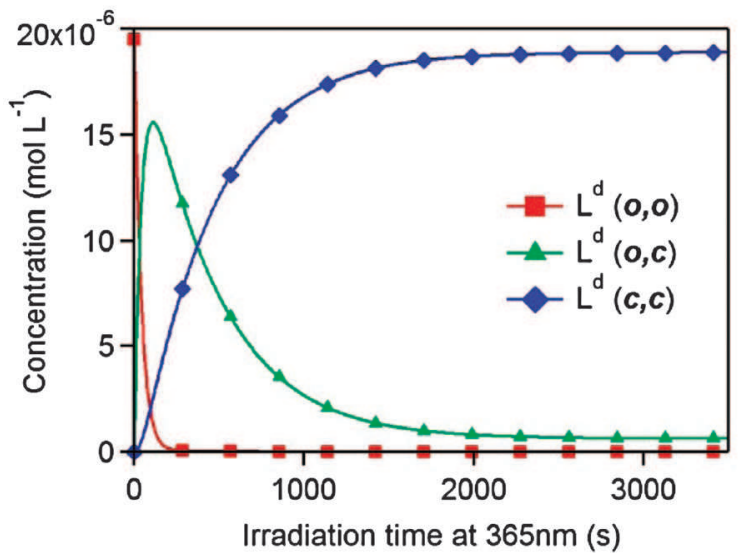

presented above, the efficiency of the reaction is strongly reduced for the second step. ${ }^{37}$ This allows us to reproduce the changes in the molar concentration of the three forms in solution (Fig. 6 and Fig. S7, ESI $\dagger$, for retrocyclization). Interestingly, a strong cross-talk between a given open-DTE unit in the excited state and its neighbor is obvious in terms of photoreactivity, since the ring-closure of the first DTE induces a drastic decrease in the photochromic quantum yield of the second one.

Concerning the ring opening, the quantum yields were found to be identical for both retrocyclization processes, which tends to show the weak electronic coupling between the closed-DTE units through the twisted bipyridyl central bridge. Their values were found to be lower than $10^{-2}$, namely much smaller than those related to cyclization as usually reported for non-constraint DTE units (Table 4). ${ }^{38}$ They are consistent with the presence of an energy barrier in the ringopening pathway in the excited state as usually encountered and suggest high stabilization of the closed forms through formation of an extended $\pi$-conjugated system. Systematic analyses of all the compounds show a monotonous decrease in the quantum yields with increasing electron-donating ability of the end group $\mathrm{D}$, namely $\mathrm{H}<\mathrm{OMe}<\mathrm{NMe}_{2}<\mathrm{NBu}_{2}$.

Finally, kinetic studies show that the quantum yields for the photocyclization of the photochromic compounds decrease

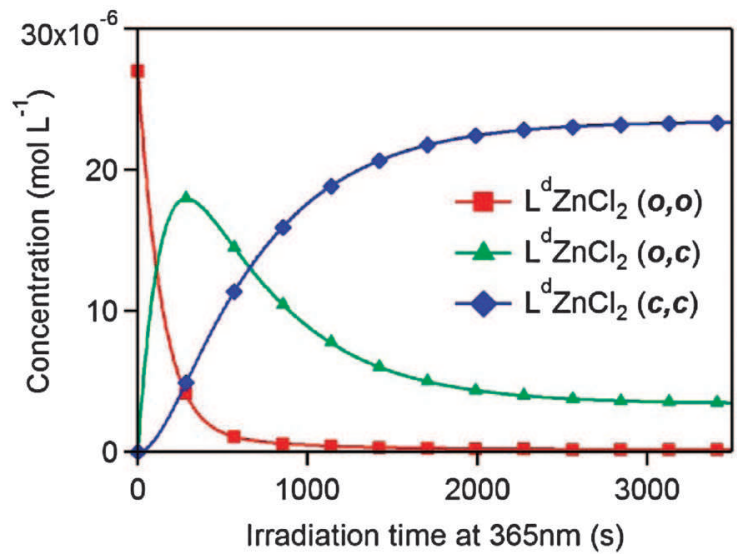

Fig. 6 Time-evolution of the concentration of the three interconverting isomers of ligand $\mathbf{L}$ (left) and complex $\mathbf{L}^{\mathbf{d}} \mathbf{Z n C l} \mathbf{Z}_{\mathbf{2}}$ (right) under irradiation at $365 \mathrm{~nm}$. 


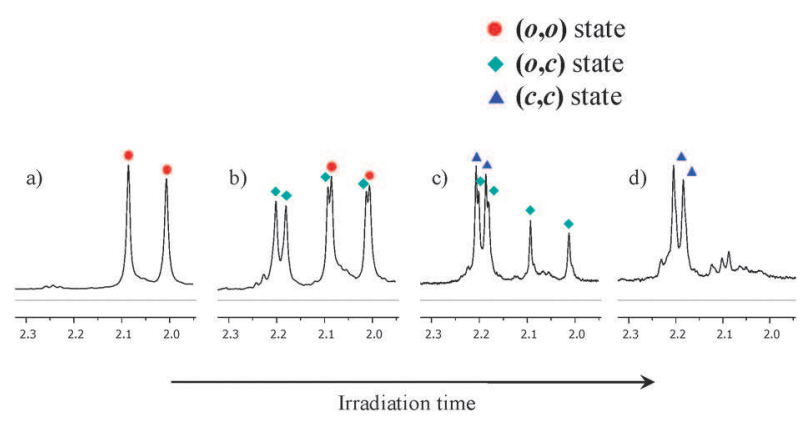

Fig. $7{ }^{1} \mathrm{H}$ NMR spectra $\left(\mathrm{CD}_{2} \mathrm{Cl}_{2}\right)$ of methyl groups of $\mathbf{L}^{\mathbf{d}} \mathbf{Z n C l}_{\mathbf{2}}$ : (a) before irradiation; (b) and (c) after successive UV irradiations; (d) at the PSS $\left(\lambda=350 \mathrm{~nm}, c=10^{-3} \mathrm{M}\right)$.

upon coordination to the $\mathrm{Zn}$ (II) center (Table 4). It appears that the configuration of the pyridine rings, transoid in the free ligand and cisoid within the $\mathrm{Zn}$ complexes, is likely to influence the efficiency of the photocyclization/cycloreversion processes: the system is more rigid in the metal complex, and consequently the geometrical rearrangement, required for photocyclization, is further impaired. Again, as in $\mathbf{L}^{\mathbf{a}-\mathbf{d}}$, the second cyclization process is significantly slower than the former one. The metal fragment $\mathbf{Z n X} \mathbf{X}_{\mathbf{2}}$ acts as a Lewis acid leading to the formation of a strong dipole $\mathrm{D}-\mathrm{A}$ and electronic effects could also play a role. It clearly points out that electronic modification of $\mathrm{D}-\mathrm{A}$ systems appears as an attractive tool to tune and control the kinetics of the photochemical processes.

As a consequence, increasing the electron-withdrawing ability of the acceptor unit by changing the ancillary acetate by chloro ligands induces a significant decrease in the ring closure quantum yields. The behavior of these push-pull systems contrasts with that of symmetrically substituted photochromic compounds, in which the incorporation of electron-withdrawing cyano substituents increases the cyclization quantum yields. ${ }^{39}$ Moreover, all these kinetic studies nicely corroborate the theoretical assumptions of photoreactivity of the intermediates $(\boldsymbol{o}, \boldsymbol{c})$ toward the doubly closed systems $(\boldsymbol{c}, \boldsymbol{c})$ by evidencing their accumulation despite the lack of characteristic spectroscopic features. Nevertheless, the kinetic data obtained for $\mathbf{L}^{\mathbf{d}} \mathbf{Z n C l}_{\mathbf{2}}$ are well-corroborated by the NMR studies. Monitoring of its photocyclization process by ${ }^{1} \mathrm{H}$ NMR spectroscopy allows us to confirm the sequential ring-closure reaction, the $\mathbf{L}^{\mathbf{d}} \mathbf{Z n C l}_{\mathbf{2}}(\boldsymbol{o}, \boldsymbol{c})$ intermediate being clearly identified. This is indicated in the spectrum by the presence of two sets of signals of equal intensity, around $2-2.3 \mathrm{ppm}$, the open and closed parts of the molecule being well-distinguishable (Fig. 7). In addition, the methyl groups' signals of the thiophene rings are well-differentiated from those of the $(\boldsymbol{o , o})$ and $(\boldsymbol{c}, \boldsymbol{c})$ forms. This study points out that electronic modification of the D-A pair appears as an appealing tool for the control of the kinetics of the photochemical processes.

\section{Conclusions}

In summary, we have demonstrated, by means of photokinetic studies, that the photochromic ring-closure/opening reactions occur in a stepwise fashion with very different consecutive quantum yields, for both the free bipyridine ligands and their corresponding $\mathrm{Zn}$ complexes. Moreover the increase in the strength of either the electron donor or acceptor group induces a strong decrease in the quantum yield of the ring-closure/ opening processes without affecting the chemical conversion yield. These studies highlight the predominant role of electronic factors as the key parameters in tuning photochromic properties and kinetics of photocyclization. These studies provide original perspectives on the use of photochromic metal complexes and charge-transfer ligands for elaborating tunable and photoswitchable nonlinear optically active systems.

\section{Acknowledgements}

This work has been financially supported by ANR (BLANC COMET). LO thanks the Région Bretagne for a PhD grant.

\section{Notes and references}

1 M. Irie, Chem. Rev., 2000, 100, 1685-1716.

2 Y. Hasegawa, T. Nakagawa and T. Kawai, Coord. Chem. Rev., 2010, 254, 2643-2651.

3 V. Guerchais, L. Ordronneau and H. Le Bozec, Coord. Chem. Rev., 2010, 254, 2533-2545.

4 L. Shen, C. Ma, S. Pu, C. Cheng, J. Xu, L. Li and C. Fu, New J. Chem., 2009, 33, 825-830.

5 A. Peters and N. R. Branda, Adv. Mater. Opt. Electron., 2000, 10, 245-249.

6 T. Kawai, T. Sasaki and M. Irie, Chem. Commun., 2001, 711-712.

7 T. Kaieda, S. Kobatake, H. Miyasaka, M. Murakami, N. Iwai, Y. Nagata, A. Itaya and M. Irie, J. Am. Chem. Soc., 2002, 124, 2015-2024.

8 I. Jung, H. Choi, E. Kim, C.-H. Lee, S. O. Kang and J. Ko, Tetrahedron, 2005, 61, 12256-12263.

9 C.-C. Ko, W. H. Lam and V. W.-W. Yam, Chem. Commun., 2008 , 5203-5205.

10 H. Choi, I. Jung, K. H. Song, K. Song, D.-S. Shin, S. O. Kang and J. Ko, Tetrahedron, 2006, 62, 9059-9065.

11 K. Higashiguchi, K. Matsuda, N. Tanifuji and M. Irie, J. Am. Chem. Soc., 2005, 127, 8922-8923.

12 Q. Luo, B. Chen, M. Wang and H. Tian, Adv. Funct. Mater., 2003, 13, 233-239.

13 K. Higashiguchi, K. Matsuda and M. Irie, Angew. Chem., Int. Ed., 2003, 42, 3537-3540.

14 K. Higashiguchi, K. Matsuda, M. Matsuo, T. Yamada and M. Irie, J. Photochem. Photobiol., A, 2002, 152, 141-146.

15 I. Lee, Y. You, S.-J. Lim and S. Y. Park, Chem. Lett., 2007, 36, 888-889.

16 H.-L. Wong, C.-C. Ko, W. H. Lam, N. Zhu and V. W.-W. Yam, Chem.-Eur. J., 2009, 15, 10005-10009.

17 V. W.-W. Yam, J. K.-W. Lee, C.-C. Ko and N. Zhu, J. Am. Chem. Soc., 2009, 131, 912-913.

18 K. Yagi and M. Irie, Chem. Lett., 2003, 32, 848-849.

19 S. Kobatake and M. Irie, Tetrahedron, 2003, 59, 8359-8364.

20 S. Kobatake, S. Kuma and M. Irie, Bull. Chem. Soc. Jpn., 2004, 77, 945-951.

21 J. Areephong, W. R. Browne and B. L. Feringa, Org. Biomol. Chem., 2007, 5, 1170-1174.

22 R. Arai, S. Uemura, M. Irie and K. Matsuda, J. Am. Chem. Soc., 2008, 130, 9371-9379.

23 H. Zhao, U. Al-Atar, T. C. S. Pace, C. Bohne and N. R. Branda, J. Photochem. Photobiol., A, 2008, 200, 74-82.

24 M. N. Roberts, C.-J. Carling, J. K. Nagle, N. R. Branda and M. O. Wolf, J. Am. Chem. Soc., 2009, 131, 16644-16645.

25 J. Areephong, J. H. Hurenkamp, M. T. W. Milder, A. Meetsma, J. L. Herek, W. R. Browne and B. L. Feringa, Org. Lett., 2009, 11, 721-724.

26 Y.-W. Zhong, N. Vilà, J. C. Henderson and H. D. Abruña, Inorg. Chem., 2009, 48, 7080-7085.

27 J. Areephong, H. Logtenberg, W. R. Browne and B. L. Feringa, Org. Lett., 2010, 12, 2132-2135.

28 D. Jacquemin, E. A. Perpète, F. Maurel and A. Perrier, J. Phys. Chem. Lett., 2009, 1, 434-438. 
29 D. Jacquemin, E. A. Perpète, F. Maurel and A. Perrier, J. Phys. Chem. C, 2010, 114, 9489-9497.

30 D. Jacquemin, E. A. Perpète, F. Maurel and A. Perrier, Phys. Chem. Chem. Phys., 2010, 12, 7994-8000.

31 A. Perrier, F. Maurel and D. Jacquemin, J. Phys. Chem. C, 2011, 115, 9193-9203.

32 V. Aubert, V. Guerchais, E. Ishow, K. Hoang-Thi, I. Ledoux, K. Nakatani and H. Le Bozec, Angew. Chem., Int. Ed., 2008, 47, $577-580$.

33 C. Adamo and V. Barone, J. Chem. Phys., 1999, 110, 6158-6170; M. Ernzerhof and G. E. Scuseria, J. Chem. Phys., 1999, 110, 5029-5036.

34 M. J. Frisch, G. W. Trucks, H. B. Schlegel, G. E. Scuseria, M. A. Robb, J. R. Cheeseman, G. Scalmani, V. Barone, B. Mennucci, G. A. Petersson, H. Nakatsuji, M. Caricato, X. Li, H. P. Hratchian, A. F. Izmaylov, J. Bloino, G. Zheng, J. L. Sonnenberg, M. Hada, M. Ehara, K. Toyota, R. Fukuda, J. Hasegawa, M. Ishida, T. Nakajima, Y. Honda, O. Kitao, H. Nakai, T. Vreven, J. A. Montgomery, Jr., J. E. Peralta, F. Ogliaro, M. Bearpark, J. J. Heyd, E. Brothers, K. N. Kudin,
V. N. Staroverov, R. Kobayashi, J. Normand, K. Raghavachari, A. Rendell, J. C. Burant, S. S. Iyengar, J. Tomasi, M. Cossi, N. Rega, J. M. Millam, M. Klene, J. E. Knox, J. B. Cross, V. Bakken, C. Adamo, J. Jaramillo, R. Gomperts, R. E. Stratmann, O. Yazyev, A. J. Austin, R. Cammi, C. Pomelli, J. W. Ochterski, R. L. Martin, K. Morokuma, V. G. Zakrzewski, G. A. Voth, P. Salvador, J. J. Dannenberg, S. Dapprich, A. D. Daniels, O. Farkas, J. B. Foresman, J. V. Ortiz, J. Cioslowski and D. J. Fox, GAUSSIAN 09 (Revision A.02), Gaussian, Inc., Wallingford, CT, 2009.

35 P. Flükiger, H. P. Lüthi, S. Portmann and J. Weber, Molekel 4.3, Swiss Center for Scientific Computing, Manno, Switzerland, 2000, http://www.cscs.ch/molekel/.

36 S. I. Goreslsky, Swizard program, revision 4.5, http://www.sg-chem. net/swizard; S. I. Gorelsky and A. B. P. Lever, J. Organomet. Chem., 2001, 635, 187-196.

37 A. Tomari, T. Yamaguchi, N. Sakamoto, Y. Fujita and M. Irie, Chem. Lett., 2004, 33, 1380-1381.

38 S. Kobatake and M. Irie, Tetrahedron, 2003, 59, 8359-8364.

39 M. Irie, K. Sakemura, M. Okinaka and K. Uchida, J. Org. Chem., 1995, 60, 8305-8309. 